\title{
Planeamiento metropolitano heterodoxo: la operatividad estratégica de la casuística argentina reciente
}

\author{
Planejamento metropolitano heterodoxo: estratégias operacionais da \\ casuística argentina recente
}

Heterodox metropolitan planning: operational strategies of the recent Argentine casuistry

Pablo Elinbaum[a] (1)

[a] Centro de Estudios Urbanos y Regionales (CEUR), Consejo Nacional de Investigaciones Científicas y Técnicas (CONICET), Buenos Aires, Argentina

Cómo citar: Elinbaum, P. (2020). Planeamiento metropolitano heterodoxo: la operatividad estratégica de la casuística argentina reciente. urbe. Revista Brasileira de Gestão Urbana, 12, e20190371. https://doi.org/10.1590/2175-3369.012.e20190371

\section{Resumen}

Los planes metropolitanos no se pueden tipificar, aunque en la bibliografía especializada aún prevalecen los ejemplos del "Norte". Más allá de las diferencias de contenido, estos planes comparten marcos estatales sostenidos por enormes estructuras de leyes y regulaciones. Pero, ¿qué sucede con las iniciativas de ordenación metropolitana que no cuentan con el apoyo de semejantes orquestaciones institucionales, tal como se da en los países latinoamericanos? A partir de un estudio de caso comparado de la casuística argentina, intentaremos echar luz sobre estas cuestiones, indagando en la especificidad del planeamiento metropolitano, para contribuir a los marcos de investigación y práctica en el contexto latinoamericano. Considerando tres dimensiones analíticas -la institucional, la instrumental y la procesal- indagamos en las particularidades de un enfoque tecnológico que, tentativamente, denominamos "heterodoxo" y cuya singular operatividad radica en la capacidad para conjugar de forma innovadora proyectos y estrategias, y para aprovechar la liviandad institucional con la que potenciar la flexibilidad de formas y procesos.

Palabras clave: Planeamiento metropolitano. Marcos institucionales. Innovación instrumental.

\section{Resumo}

Os planos metropolitanos não podem ser tipificados, embora exemplos do "Norte" predominem na bibliografia especializada. Além das diferenças de conteúdo, esses planos compartilham estruturas estatais suportadas por enormes estruturas de leis e regulamentos. Mas o que acontece com as iniciativas da organização metropolitana que não contam com o apoio de orquestrações institucionais similares, como ocorre nos países da América Latina? Com base em um estudo de caso comparativo da casuística argentina, tentaremos esclarecer essas questões, investigando a especificidade do planejamento metropolitano, para contribuir com as estruturas de pesquisa e prática no contexto latino-americano. Considerando três dimensões analíticas - institucional, instrumental e processual -, investigamos as particularidades de uma abordagem tecnológica, que tentativamente chamamos de "heterodoxa", e cuja operação única reside na capacidade de combinar projetos e estratégias de uma maneira inovadora e de tirar vantagem de leveza institucional para aumentar a flexibilidade de formas e processos.

Palavras-chave: Planejamento metropolitano. Marcos institucionais. Inovação instrumental. 


\begin{abstract}
Metropolitan plans cannot be typified, although the examples from the "North" prevail in the specialized bibliography. Besides the content differences, the northern plans share state frameworks underpinned by huge structures of laws and regulations. But what happens to the initiatives of metropolitan organization that do not count on the support of similar institutional orchestrations, as occurs in the Latin American countries? Based on a comparative case study of Argentine casuistry, this study aims to shed light on these questions, inquiring into the specificity of metropolitan planning, to contribute to research and practice frameworks in the Latin American context. Considering three analytical dimensions: institutional, instrumental and procedural, it inquiries into the particularities of a technological approach, which it was tentatively call "heterodox", and whose unique operation lies in the ability to combine projects and strategies in an innovative way, and to take advantage of institutional lightness to enhance the flexibility of forms and processes.
\end{abstract}

Keywords: Metropolitan planning. Institutional frameworks. Instrumental innovation.

\title{
Introducción
}

Cien años pasaron desde que Patrick Geddes introdujo el concepto de conurbación para describir el producto más cabal de la civilización industrial: las metrópolis. A un siglo de la publicación de Cities in evolution (Geddes, 1915), ¿cuál fue el derrotero de esta indagación seminal? La genealogía de los estudios sobre "lo metropolitano" podría explicarse a partir dos direcciones generales. Por un lado, la que seguían los enfoques positivistas, como los de Blumenfeld (1968) y Gottmann (1961), que pretendían cuantificar el tamaño y la población ideal de las metrópolis modernas y, por otro, la orientación cualitativa de las descripciones geográficas y morfológicas, en general, enfocadas desde reflexiones postmodernas, entre las que podemos destacar la citta territorio de Giancarlo De Carlo y Ludovico Quaroni (De Carlo \& Quaroni, 1962) o el fet metropolità de Juli Esteban (1991). La vigencia de ambas exploraciones se mantiene hasta hoy, por un lado, en los rankings anuales de las grandes ciudades que realiza el Banco Mundial y, por otro, en la creación arrolladora de nuevos conceptos como región-urbana, ciudad-global, postmetropolis, hiperciudad, metápolis, entre varios de los neologismos que recogía Joan Vicente (2003), a principios de este siglo. Más recientemente, los investigadores han movido el foco desde las formas a los procesos para estudiar lo que algunos denominan "metropolización". En líneas generales, este fenómeno da cuenta de la relación entre las reestructuraciones urbanas y las dinámicas globales que guían la transición del régimen económico fordista al postfordista (De Mattos, 2001; Indovina, 2007; Orellana Ossandón et al., 2013; Nel·lo, 2017; entre otros autores).

Pese a estos significativos aportes, en la bibliografía especializada, sin embargo, resulta más difícil encontrar investigaciones sobre el planeamiento metropolitano. La mayoría de los trabajos existentes se refieren a los estudios de caso de las grandes ciudades capitales como, por ejemplo, Roma (Marcelloni, 2002), Barcelona (Esteban, 2012), París (Fouchier, 2010), Amsterdam (Alexander, 2002) y Londres (Simmons, 2000). Entre los pocos estudios comparados y sistemáticos, cabe destacar aquellos que se apoyan en indicadores cuantitativos como los del Programa METREX (2007), en enfoques sectoriales como los que estudian las redes de transporte y servicios (ej. Julià, 2006; Programa TEN-T), las miradas sociológicas que identificaron el surgimiento de las ciudades globales con el auge del planeamiento estratégico metropolitano en los noventas (Ren \& Keil, 2017; Soja, 2000); y los compendios de la Unión Europea sobre las políticas públicas en múltiples niveles administrativos (European Union, 1997; Farinós, 2006). En cuanto a las aproximaciones cualitativas -aquellas que intentan atar las formas y los procesos con las prácticas- destacamos las investigaciones de Abadia (2002), De Miguel González \& Ezquiaga (2012), Healey (2006), Balducci et al. (2017), Elinbaum \& Galland (2016) y, sobre todo, los aportes Christian Lefèvre (2009), pionero en el análisis de la gobernanza y la institucionalidad metropolitana. 
En el contexto de América Latina, sucede algo similar a lo que ya mencionamos. La mayoría de las investigaciones sobre el planeamiento metropolitano se enfocan en las cuestiones de la gestión, desde miradas económicas e institucionales asociadas a los problemas de la gobernanza y la competitividad (Rojas et al., 2005), o en estudios de casos individuales, entre los que vale la pena mencionar la compilación editada por Juan Ramón Selva (2017) en el no 13 de la Revista Iberoamericana de Urbanismo que incluye los casos de Santiago, Montevideo, Lima y Rosario. Lo que decanta de todas estas investigaciones es que, a diferencia de los planes urbanos municipales -concebidos a partir de códigos y normas estandarizadas-, los planes metropolitanos no pueden tipificarse, sino que deben redefinirse en cada ejercicio de planeamiento (Elinbaum, 2016 y 2018). Sin embargo, entre las referencias más citadas aún prevalecen los paradigmas del "Norte": planes canonizados como el del Gran Londres (1944), el Schema Directour de París (1965) o el Plan de los Dedos de Copenhague (en danés, Fingerplanen) de 1947 -todos ellos implementados durante el período desarrollista de mediados del siglo XX. Más allá de las tradiciones disciplinares de los distintos países europeos ${ }^{1}$, los planes que "hicieron escuela" convergen en el contexto institucional de su implementación: marcos burocráticos sostenidos por la enorme orquestación de leyes, regulaciones y proyectos estatales que demandaba la economía industrial fordista en plena expansión.

Pese al auge de otros enfoques contemporáneos, como el del planeamiento estratégico, la aproximación racional-comprehensiva permanece como el principal referente tecnológico tanto en la investigación básica como en el diseño de las políticas públicas supralocales. Sin embargo, la definición del planeamiento metropolitano como objeto de estudio no solo está sesgada por el formalismo modernista, sino también por las tradiciones autorreferenciales de la casuística del Norte Global: sistemas de planeamiento que operan bajo el paraguas institucional de la Unión Europea, considerado a menudo como el ideal de articulación interadministrativa (Galland \& Elinbaum, 2018; Elinbaum \& Galland, 2017). Pero, ¿cómo se diseñan e implementan las políticas metropolitanas cuando los sistemas de planeamiento no están formalizados, tal como suele suceder en los países latinoamericanos?, ¿es posible planificar por fuera -o sin necesidad- de marcos instrumentales y normativos estables e integrados?, ¿existen otras formas de operatividad que no dependan del andamiaje burocrático de procedimientos y leyes?, en definitiva, ¿qué podemos aprender de experiencias tan heterogéneas e incipientes como la de los planes latinoamericanos?

A partir de estos interrogantes, el objetivo de este artículo apunta a contribuir a los marcos de investigación y de la práctica del planeamiento metropolitano, para mostrar cómo la operatividad y la innovación tecnológica no dependen solo de los marcos institucionales e instrumentales integrados o de los procedimientos plenamente formalizados. En particular, apuntamos a discutir la especificidad del planeamiento metropolitano en América Latina, concibiéndolo como una práctica situada en su contexto, más que aislada o periférica con respecto a los paradigmas del Norte Global. Con este fin, a partir de un estudio de caso comparado de la casuística argentina, exploraremos los marcos institucionales, el funcionamiento de los instrumentos y el proceso de elaboración del planeamiento, para identificar sus aspectos más operativos y estratégicos. Pretendemos, en este sentido, mostrar cómo esta aproximación tecnológica, que tentativamente denominaremos "heterodoxa", por su familiaridad con el modelo de planeamiento no-euclidiano de John Friedmann (1993), aprovecha la flexibilidad y liviandad institucional para articular la coordinación vertical con la cooperación horizontal; sintetizar las regulaciones de los tres niveles administrativos de gobierno, combinar diferentes metodologías de planeamiento, y construir la agenda metropolitana a partir de la realización de obras concretas, garantizando un horizonte realista en el actual remolino de incertidumbre política y económica.

\footnotetext{
${ }^{1}$ Según Nadin \& Stead (2008), dentro de Europa, podemos distinguir cuatro grandes tradiciones de planeamiento: ComprehensivoIntegrado, Urbanístico, Económico-Regional y Regulación del Uso del Suelo. Dentro de estas tradiciones existen, obviamente, matices regionales e históricos. Así, dentro del estilo "Urbanístico" podemos distinguir el enfoque disciplinar italiano del español. Este último, por ejemplo, cuenta con una genealogía específica del planeamiento y su propia generación de planes: de aprovechamiento edilicio, remediales y morfológicos (Font, 2000). Asimismo, cada país europeo muestra combinaciones de las “tradiciones ideales”. Por ejemplo, España se considera un país con una tradición urbanística y, al mismo tiempo, se lo asocia a la tradición de la regulación del uso del suelo, por el legalismo que caracteriza su estatalidad (Farinós, 2006).
} 
Esta investigación parte de un enfoque cualitativo y se apoya en la técnica del análisis comparado. El planeamiento en las áreas metropolitanas de Rosario y Mendoza, los dos casos seleccionados, coinciden en seis condiciones tipológicas: (1) ambos casos son coetáneos; (2) se enmarcan en el Programa de Desarrollo de Áreas Metropolitanas del Interior (DAMI)2; (3) presentan instituciones específicas para la coordinación metropolitana; (4) superan el tradicional enfoque sectorial de las políticas públicas supralocales; (5) han recibido el reconocimiento internacional, sobre todo, la experiencia del urbanismo rosarino, presentada en la Bienal de Venecia; y (6) son claros exponentes de áreas metropolitanas de territorios relativamente diversificados, heterogéneos, con sectores dinámicos y atrasados, coexistiendo en el marco de una renovada inserción semi-periférica, propiamente latinoamericana. Para el análisis de estos casos se recurrió a fuentes secundarias como la documentación de los planes, las leyes y normas vigentes en cada contexto, la bibliografía especializada sobre los casos, y diferentes fuentes públicas como las que se informan en los portales oficiales de los organismos estatales. Asimismo, el análisis se apoya en una serie de entrevistas semi-estructuradas realizadas a los técnicos clave en cada caso.

El artículo se estructura en cuatro partes. Después de la introducción, en el segundo apartado se explica el marco conceptual y metodológico para el análisis empírico, a partir de tres dimensiones analíticas: la institucional, la instrumental y la procesal. En el tercer y cuarto apartado se desarrollan los estudios de caso. Por último, se cruzan y discuten los resultados para concluir con una serie de observaciones convergentes en los casos, sugiriendo posibles caminos para las futuras investigaciones.

\section{Tres dimensiones del planeamiento metropolitano}

¿Cómo se analizan los planes metropolitanos? A partir de la revisión de la bibliografía especializada, en este apartado se recopilan los principales antecedentes internacionales y referencias de investigación en matéria de diseño e implementación de planes urbanos y de ordenamiento territorial. Como fruto de ese diálogo teórico y metodológico, se sugiere una serie de dimensiones y variables analíticas que apuntan a evaluar el alcance y el contenido de los planes metropolitanos contemporáneos, adecuados al objetivo de este artículo. Partiendo del estudio canónico de Faludi \& Van der Valk (1994), se proponen tres dimensiones analíticas -el contexto institucional, el contenido instrumental y el proceso de planificación (ver Tabla 1 ). ${ }^{3}$

Desde el punto de vista institucional, los planes metropolitanos se caracterizan por el entramado de los organismos que participan en su diseño e implementación y por los marcos legales de cada país (Newman \& Thornley, 1996; European Union, 1997). Dicho de otro modo, el planeamiento -sus políticas y modelos- reproduce en esencia las estructuras institucionales y los sistemas normativos a través de los cuales se desarrolla (Janin Rivolin, 2008). Estos marcos pueden ser de dos tipos: "conformativos" o "movilizadores"4. Los primeros se caracterizan por un enfoque tradicional y amplio, que aspira a "conformar" proyectos unitarios en una estrategia integral, en la cual los actores están obligados a participar. Los marcos movilizadores, en cambio, están menos institucionalizados; promueven aquellos proyectos capaces de "movilizar" una estrategia desestructurada donde los actores son invitados a participar (Janin Rivolin, op. cit., p. 167). De este modo, las instituciones involucradas podrían estar

\footnotetext{
${ }^{2}$ Los casos de Mendoza y Rosario han sido seleccionados, por su madurez institucional y técnica, en el marco del proyecto de investigación "La Práctica del Planeamiento Metropolitano" (PICT 0904 - Ministerio de Ciencia y Técnica) en el cual se estudian y comparan las experiencias de planeamiento de las 14 principales áreas metropolitanas argentinas, desarrolladas bajo la dirección del Programa DAMI. El Programa DAMI -dependiente del Ministerio del Interior, Obras Públicas y Vivienda- tiene como propósito contribuir a mejorar el funcionamiento de los servicios en las áreas metropolitanas del interior (AMI). Véase: Buenos Aires (2019).

${ }^{3}$ Las dimensiones elegidas se basan no solo en las contribuciones de los tratadistas, sino también en las aportaciones metodológicas del autor de este artículo, en la construcción de un protocolo analítico madurado en la práctica -desde la cocina del planeamiento-y a partir del análisis de diversos casos europeos y latinoamericanos, en el marco de una línea de investigación desarrollada a lo largo de más de quince años de discusiones en congresos, proyectos de investigación y artículos científicos.

${ }^{4}$ Creemos que son éstos los términos que mejor se ajusten al concepto original en inglés: conformative y performative.
} 
"conformadas" por una institución monolítica (única) o "movilizadas" por una coalición de actores involucrados en el proceso de elaboración del plan (Faludi \& Van der Valk, 1994; Roodbol-Mekkes et al., 2012; van Duinen, 2013).

Además, las instituciones de planeamiento están dotadas con diferentes tipos de instrumentos. Cuando nos referimos a su contenido, de forma resumida, podemos hablar de dos clases de planes: los generales y los especiales (Esteban, 1998). Los primeros combinan una amplia gama de temas y toman como ámbito de intervención una jurisdicción completa, ya sea un municipio, una provincia o un país. Por su parte, los planes especiales tienen un contenido más bien sectorial y afectan solo a una porción del territorio que, en general, se delimita de forma ad hoc. Los planes urbanos también se caracterizan por su alcance -o efecto- que puede ser vinculante o indicativo, cuando sus prescripciones no sean obligatorias. Otro instrumento a destacar son los modelos espaciales que permiten prever dos tipos de desarrollo: el monocéntrico que sigue el patrón radial de las ciudades industriales, tal como lo definió Christaller (1966), y el policéntrico que se da cuando los núcleos que conforman las áreas metropolitanas tienden a equilibrar su peso urbano y a vincularse en red (Meijers et al., 2003; Neuman \& Hull, 2009). Las representaciones espaciales y los discursos también cumplen un papel instrumental clave (van Duinen, 2004). Por su carácter estratégico -entre la coordinación y la cooperación-, son fundamentales no solo para explicar los proyectos durante el proceso de elaboración de los planes, sino también para argumentar la territorialidad de los nuevos espacios estatales como el de las áreas metropolitanas en vías de institucionalización (Faludi, 1996; Neuman \& Hull, 2009).

Dentro del proceso de planeamiento, también destacamos el papel de la programación de los objetivos y la definición de los escenarios de desarrollo, conceptualizados por Faludi (2000) como "elementos temporales". Es a través de estos elementos que los planes pueden concebirse de forma incremental (como pasos encadenados para alcanzar los resultados en el horizonte previsto) o de forma opcional, cuando se prevén caninos alternativos de implementación (Faludi, 2000). Además, el proceso de planeamiento depende en buena medida de los papeles que adoptan los planificadores y de cómo éstos caracterizan los estilos profesionales. Para simplificar su definición, tal como las describen Faludi \& Van der Valk (1994), los clasificaremos a partir de dos actitudes genéricas -la tecnocrática y la participativa-, haciendo la salvedad de que nunca son puras, sino que tienden a combinarse en la práctica.

A partir de estas dimensiones y variables analíticas, en el próximo apartado se analizan los dos casos de estudio seleccionados, comenzando por el del Área Metropolitana de Rosario.

Tabla 1 - Dimensiones, variables y parámetros del planeamiento metropolitano

\begin{tabular}{ccc}
\hline Dimensión & Variable & Parámetro \\
\hline Contexto Institucional & Marco legal & Conformativo vs. Movilizador \\
& Instituciones involucradas & Monolítico vs. Coalición \\
Contenido Instrumental & Contenido temático & General vs. Especial \\
& Forma/efecto & Vinculante vs. Indicativo \\
Proceso de Planeamiento & Escenarios & Incremental (fases) vs. Opcional \\
& Papel de los técnicos & Tecnocrático vs. Participativo \\
\hline
\end{tabular}

Fuente: Elaboración propia a partir de las categorías propuestas por los autores citados en este apartado.

\section{El planeamiento del Área Metropolitana de Rosario: la mirada desde abajo}

El Área Metropolitana de Rosario (AMR) comprende un conjunto dinámico y heterogéneo de localidades ubicadas al sur de la provincia de Santa Fe, atadas por su interdependencia funcional y por un conjunto de problemas en común. Entre los más acuciantes, se destacan el déficit de viviendas, la contaminación por el uso de agroquímicos y la saturación de las rutas producida por el transporte de mercancías. Estos problemas y procesos han sido estudiados en distintas instancias, reconociendo la dinámica singular que le imprime Rosario, la ciudad central, y el papel que juega en su consolidación el conjunto de localidades que la rodean, conformando una estructura tentacular que se extiende, en 
sentido este-oeste, sobre el frente pampeano y, en sentido norte-sur, como un cordón lineal recostado sobre la vera del río Paraná (Figura 1).

La institucionalidad del AMR se consolida en la primera década del siglo XXI a partir del proceso de planeamiento estratégico sostenido gracias a la continuidad del Partido Socialista en Rosario y luego en la Provincia. Experiencias como el Plan Estratégico Provincial (PET-2030) y Plan Estratégico Rosario Metropolitana (PERM+10) dieron pie en 2012 a la creación del Ente de Coordinación Metropolitana de Rosario (ECOM). El ECOM nuclea de forma voluntaria a 26 localidades organizadas en un consejo de gobierno formado por todos los intendentes ${ }^{5}$, un directorio constituido por cinco jefes de gobierno que van rotando y una presidencia reservada para el intendente de Rosario. En 2016, la Ley de Áreas Metropolitanas confirmó este organigrama, reforzando aún más la autarquía del ECOM.

Pese a su conformación institucional, en la práctica, el funcionamiento del ente se moviliza a través de una coalición de actores cuya cohesión nunca está garantizada. Para integrar a los intendentes fue necesario enfocar la cooperación intermunicipal exclusivamente a través de cuestiones técnicas y, sobre todo, de proyectos concretos. En este sentido, cabe destacar el papel de la secretaría ejecutiva del ECOM -la Oficina Metropolitana- encargada de la gestión del planeamiento urbano y de los proyectos de alcance supralocal como, por ejemplo, la reconversión de la Ruta 21 en la avenida interurbana del Corredor Sur actualmente en obra (Figura 2).

Los proyectos ejecutados y el apoyo técnico cotidiano fueron perfilando al ECOM como un mediador entre las localidades y la provincia, afianzando el arraigo institucional de los 26 intendentes. Sin embargo, para sostener semejante coyuntura política y garantizar la horizontalidad puntillosa de los jefes de gobierno en el marco del Consejo Directivo del ECOM, durante los primeros cinco años de gestión, fue necesario amputar el municipio de Rosario del mapa metropolitano, liberando el peso de su macrocefalia urbana, administrativa y política.

Este enfoque estratégico se combina con otro más urbanístico, propio de los arquitectos. Así, en 2014, los técnicos del ECOM diseñaron las Directrices de Ordenación Territorial (DOT), formuladas a partir de los tres sistemas generales del planeamiento físico: espacios libres, infraestructuras de servicio, y tejidos urbanos. Pese al carácter indicativo de estos temas, las directrices hacen hincapié en contenidos especiales, específicamente metropolitanos, evitando la superposición con los planes urbanos locales. Desde esta perspectiva, los espacios libres se centran en el tratamiento del suelo periurbano; la movilidad se enfoca desde el diseño del transporte de cercanías y las áreas logísticas; y las áreas residenciales e industriales se conciben a partir de una nueva estructura urbana metropolitana que articula los proyectos aislados de cada municipio.

\footnotetext{
${ }^{5}$ El Área Metropolitana de Rosario está conformada por los municipios de: Acebal, Álvarez, Alvear, Andino, Arroyo Seco, Capitán Bermúdez, Coronel Domínguez, Fighiera, Funes, General Lagos, Granadero Baigorria, Ibarlucea, Pérez, Piñero, Pueblo Esther, Ricardone, Rosario, San Lorenzo, Soldini, Villa Gobernador y Zavalla. El AMR concentra más de 1.400 .000 habitantes que residen en un espacio que ocupa cerca de $2.200 \mathrm{~km}^{2}$ de superficie.
} 


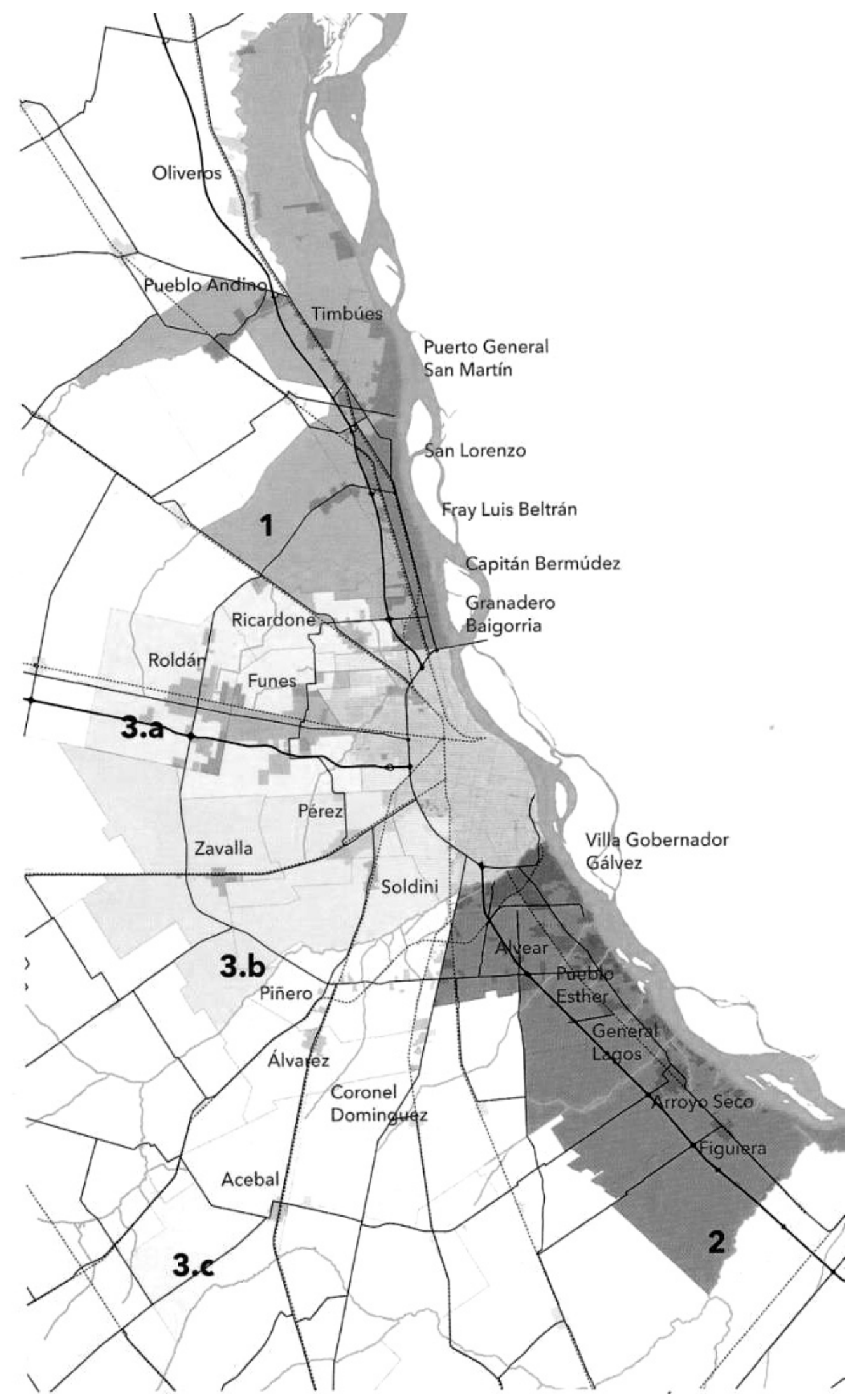

Figura 1 - Reequilibrando la macrocefalia: Sub-sistemas urbanos del Área Metropolitana de Rosario sin Rosario. Los Sub-sistemas del AMR son: (1) Corredor Norte, (2) Corredor Sur, (3.a) Corredor Noroeste, (3.b) Cuadrante Oeste y (3.c) Cuadrante Sur. Fuente: Archivo del ECOM, 2018. 

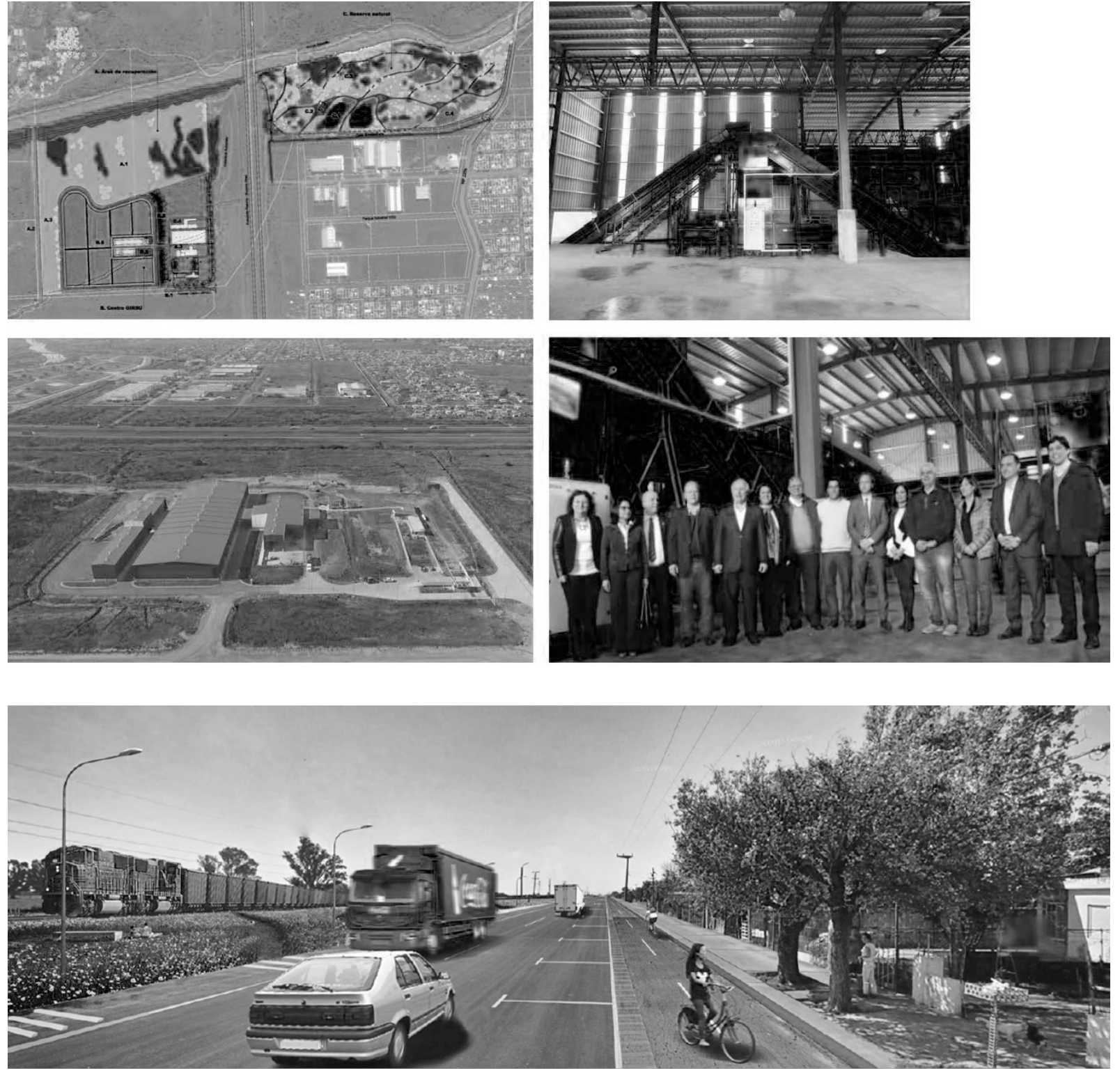

Figura 2 - Dos obras de alcance supralocal gestionadas y ejecutadas a través del ECOM. Véase, arriba, el Centro GIRSU y, abajo, el proyecto de reconversión de la Ruta 21 en vía cívica. Fuente: Archivo del ECOM, 2018.

La especificidad temática de las DOT, sin embargo, no fue suficiente como para transformarlas en un plan metropolitano. La delicada coyuntura entre los intendentes demandaba otra estrategia. Así, se optó por implementarlas desde abajo, a partir de la redacción de los planes urbanos para todas las localidades, previendo a su vez que éstos incluyan los objetivos, criterios y propuestas de las DOT (Figura 3). De este modo, la sumatoria de los planes locales resultaría "de hecho" en el plan metropolitano, sin la necesidad de imponerlo desde arriba. Aún así, el gobierno provincial reservó tres temas estratégicos para tratarlos mediante leyes sectoriales. Estos son: la protección de los frentes fluviales, el respaldo jurídico de las vías interurbanas y la delimitación precisa de las áreas de expansión de la planta urbana. En este último caso, cabe señalar que la regulación del suelo se concibe en términos más estratégicos que normativos. Es decir, no se trata de imponer la forma de la expansión en cada localidad, sino de que los intendentes "reaccionen" -realizando un proyecto oportuno para el municipio-, anticipándose a los desarrolladores inmobiliarios. 


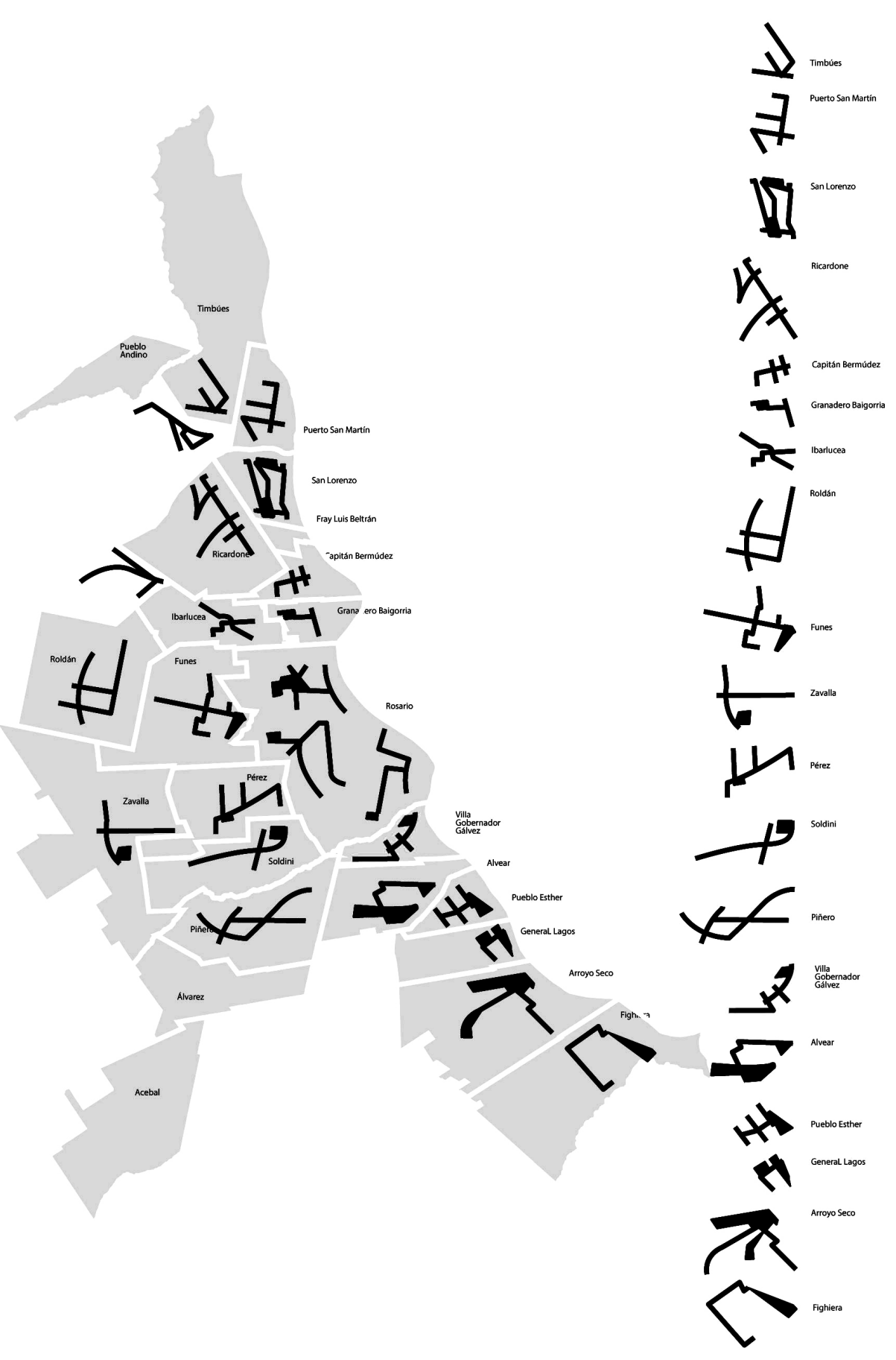

Figura 3 - Estrategias locales. Plano de pictogramas que representa la horizontalidad de las localidades, su carácter único e irremplazable, como si fuesen las piezas que conforman el puzle del proyecto metropolitano. Fuente: Documento de trabajo, Archivo del ECOM, 2016.

Si bien las DOT están pensadas para la acción y para la gestión urbanística, hasta la fecha, los técnicos del ECOM no han fijado un programa de intervenciones ni han definido escenarios de desarrollo. La construcción de la agenda común metropolitana demanda que primero se aprueben todos los planes urbanos locales. Este proceso, aún en marcha, contempla instancias participativas en dos niveles, el del Consejo de Intendentes y el de los talleres ciudadanos realizados durante la elaboración de los planes urbanos en cada localidad. Asimismo, los técnicos del ECOM aprovechan estos talleres para divulgar los aspectos supramunicipales de cada plan local, anticipando el nuevo régimen estatal metropolitano. Dentro del proceso participativo, cabe 
destacar la comunicación continua de los resultados concretos, sistemáticamente publicados en libros y folletos de divulgación, que han permitido incluso que los intendentes obtengan su propio rédito político.

Es en este punto donde el caso del ECOM evidencia cómo la escala indefinida de lo metropolitano demanda un reequilibrio continuo entre las formas y los procesos. Veamos a continuación cómo se ajustan estos términos en la experiencia del planeamiento metropolitano de Mendoza.

\section{El planeamiento del Área Metropolitana de Mendoza: la mirada desde arriba}

Con más de un millón de habitantes, el Área Metropolitana de Mendoza (AMM) es la principal conurbación del oeste argentino y la cuarta del país. Está compuesta por los municipios de Las Heras, Guaymallén, Godoy Cruz, Maipú, Luján de Cuyo y Ciudad de Mendoza, concentrando más del $65 \%$ de la población de la provincia y ocupando $168 \mathrm{~km}^{2}$ extendidos de forma casi regular hasta las estribaciones de la precordillera de los Andes 6 . Por su localización estratégica en el sistema nacional de ciudades y en el corredor Bioceánico, el Área Metropolitana de Mendoza es un importante prestador de bienes y servicios tanto a nivel local, regional e internacional. En los últimos cuarenta años ha experimentado un crecimiento demográfico, urbano y económico que provocó transformaciones en su estructura metropolitana, resultando en un modelo de ciudad dispersa y de baja densidad que hoy comienza a manifestar sus efectos negativos (expansión urbana descontrolada, avance hacia las tierras de cultivo, desarticulación modal del servicio de transporte público e ineficiencia en la gestión de los recursos naturales, entre otros problemas acuciantes).

Para enfrentar estas cuestiones, el gobierno provincial mendocino promulgó en 2006 la Ley $\mathrm{N}^{\circ} 8051$ de Ordenamiento Territorial y Usos del Suelo, pionera en el contexto nacional. Este proceso de planeamiento, que contó con una amplia participación pública e institucional, culminó en 2017 con la aprobación del "Plan Provincial de Ordenamiento Territorial” (PPOT). Durante este proceso, que duró más de diez años e incluyó ejercicios de planeamiento estratégico movilizados por coaliciones del sector privado (Plan Mendoza 2010 y Mendoza 2030), el gobierno provincial creó en 2015 el Consejo Metropolitano de Coordinación de Políticas Públicas (UNICIPIO), articulando de forma fáctica y empírica el proyecto del Área Metropolitana de Mendoza con los objetivos del PPOT.

UNICIPIO está presidido por el Secretario de Ambiente y Ordenamiento Territorial de la Provincia de Mendoza e involucra a una Coordinadora Provincial, a los siete intendentes en calidad de vocales y a los respectivos coordinadores técnicos municipales. El Área Metropolitana de Mendoza alberga condiciones territoriales muy favorables al momento de conformar la articulación institucional y una integración interjurisdiccional equilibrada y policéntrica. En primer lugar, porque la Capital de la Provincia, el municipio de Ciudad de Mendoza, no presenta características macrocefálicas como la mayoría de las áreas metropolitanas del país (Figura 4) y, en segundo lugar, porque la población y los recursos se encuentran equitativamente esparcidos a lo largo de un territorio con características compactas. Lejos de la pureza de los modelos espaciales, por razones de funcionalidad territorial en cuanto a la gestión de la red hídrica, se decidió incluir al municipio de Lavalle que se encuentra aislado de las seis localidades que conforman la aglomeración metropolitana.

\footnotetext{
${ }^{6}$ En un marco geográfico, cabe destacar que Mendoza es una zona árida, donde las actividades urbanas y productivas se desarrollan en los oasis (Norte, Centro y Sur). Los oasis ocupan el 4\% del territorio mendocino; el Área Metropolitana de Mendoza se ubica en el oasis Norte.
} 


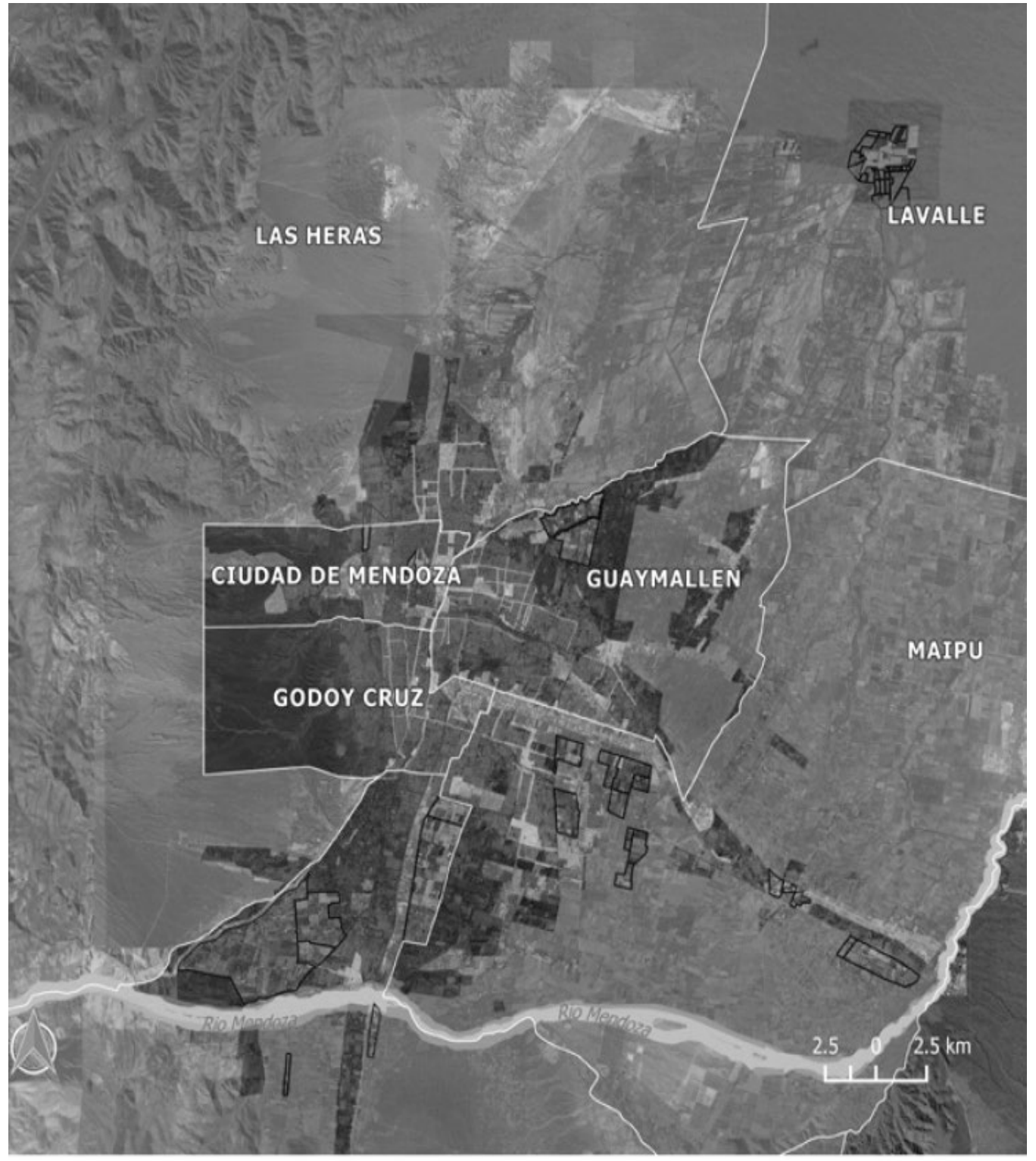

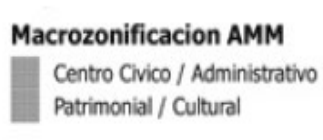

Patrimonial / Cultural
Residencial
Comercial

Industrial

Servicio / Equipamiento

\section{Seguridad}

Esparcimiento / Recreacion

Area Protegida / de Reserva

Natural

Figura 4 - Distribución de usos del suelo en el Área Metropolitana de Mendoza. Véase la posición y el tamaño relativamente pequeño de la Ciudad de Mendoza -la capital-en relación a las otras localidades metropolitanas. Fuente: Plan de Acción. UNICIPIO, 2018.

La institución fue bien recibida por los intendentes quienes desde el inicio avalaron políticamente el proyecto unitario. Aunque son los aspectos técnicos, tratados en las diferentes mesas de gestión, los que han permitido consolidar la identidad de pertenencia de los siete municipios al ente metropolitano, aún cuando coexisten diferentes colores políticos. Como fruto de la articulación técnica, cabe mencionar la creación de dos instancias de administración interjurisdiccional, planteadas con un enfoque estrictamente sectorial: una enfocada en cuestiones de seguridad (CO.ME.SEG) y la otra en la gestión del arbolado público (MEGAP).

Durante sus dos primeros años de vida, UNICIPIO formó parte del Programa CES (Ciudades Emergentes Sostenibles) promovido por el BID que es el ente que financió el denominado "Plan de Acción 
Mendoza Sostenible". La metodología del programa se basa en un protocolo de tres etapas (diagnóstico, priorización y plan de acción), estructuradas en tres dimensiones (la medioambiental, la socio-económica y la urbano-funcional) que, a su vez, son operativizadas por una serie de temas e indicadores previamente fijados. Estos últimos se califican a través de un mecanismo de semaforización que indica las áreas sostenibles de la ciudad y aquellas que necesitan mayor atención.

La etapa de priorización, quizás la más original desde el punto de vista metodológico, se basa en la selección de los 14 temas más problemáticos, "filtrados" por una encuesta de opinión pública y por la mirada interdisciplinar del equipo de especialistas (ver Figura 5). Los temas seleccionados se desagregan en líneas de acción concretas, como la gestión de los residuos, la promoción de clusters de innovación y la seguridad ciudadana, entre otros. Pese al carácter estandarizado de la metodología CES, el Plan de Acción también se articula con las políticas territorialmente situadas del PPOT, entre las que cabe destacar la revalorización del patrimonio cultural, la gestión del riesgo sísmico y la regularización de las actividades ubicadas al Piedemonte. Se trata de un sofisticado ejercicio de concurrencia del planeamiento en múltiples escalas (ver Figura 6), donde el nivel metropolitano funciona como un conmutador que permite ligar diversas políticas, metodologías e instrumentos.

Pese al carácter minucioso de la metodología CES, las líneas del Plan de Acción no son vinculantes. Se sugiere que su programación se enfoque a partir de escenarios incrementales de desarrollo (actual, tendencial, deseable e intermedio) y en etapas que contemplan montos de inversión a corto, mediano y largo plazo (que también son orientativos). Sin embargo, las líneas de acción son más que un simple enunciado directriz, en la medida que han logrado movilizar la discusión de las cuestiones metropolitanas en las reuniones periódicas que coordina UNICIPIO con los secretarios de planeamiento y obras públicas de las siete localidades. El papel protagonista de los técnicos, en este sentido, ha sido clave para promover la consciencia acerca de la relevancia de las cuestiones supralocales y para clarificar los beneficios de la "cooperación", tanto como las limitaciones de la "des-coordinación".

Como se observa en el caso mendocino, la articulación de los actores metropolitanos está claramente liderada por y desde el sector público. Si bien UNICIPIO aún no tiene una dirección dentro de la Secretaría de Ambiente y Ordenamiento Territorial, en los pocos años que han transcurrido desde su creación, ha evidenciado una notable capacidad de gestión. El aval político del gobierno provincial le ha permitido a la Socióloga Graciela Marty -coordinadora de UNICIPIOpotenciar el trabajo integrado y participativo, en contraste al accionar tecnocrático de las históricas secretarías de planificación sectorial. Con un equipo estable de sólo tres personas, ha logrado articular acciones inmediatas y consensuadas, armar equipos ad-hoc con especialistas de las administraciones provinciales y municipales, despertando un gran interés y entusiasmo por las políticas metropolitanas.

Actualmente, el UNICIPIO comienza la etapa de ejecución de dos grandes proyectos que integran el Programa DAMI (Desarrollo de Áreas Metropolitanas del Interior): uno para la recuperación y revaloración del Arbolado Público, y otro para la creación de la red de ciclovías metropolitanas. Asimismo, se ha iniciado la formulación de otro proyecto de gran escala para la preservación del Cordón Verde Metropolitano a través de la estrategia del turismo sustentable. 


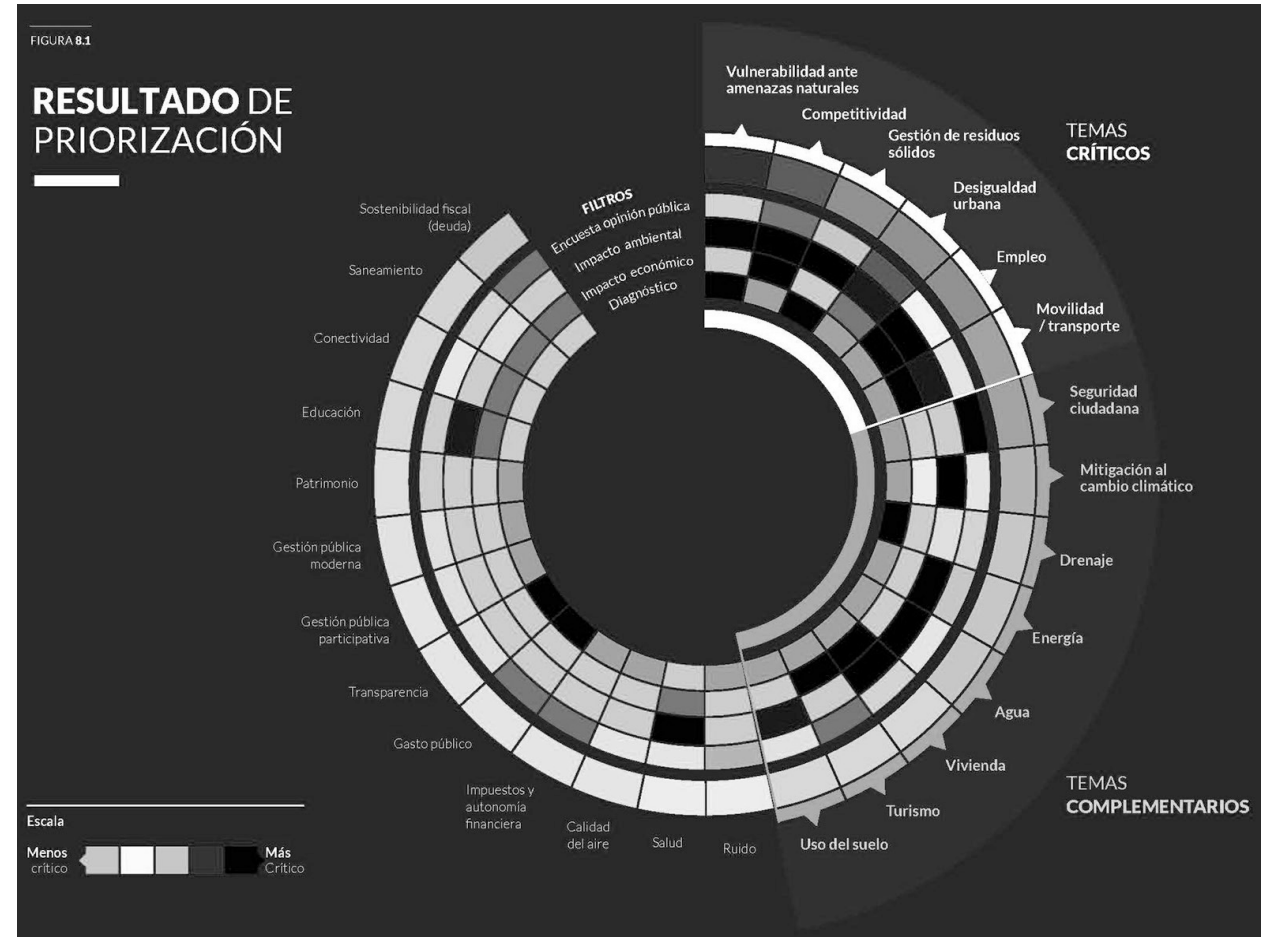

Figura 5 - Mecanismo de "filtros" para la priorización de temas y problemas. Fuente: Plan de Acción. UNICIPIO, 2018.

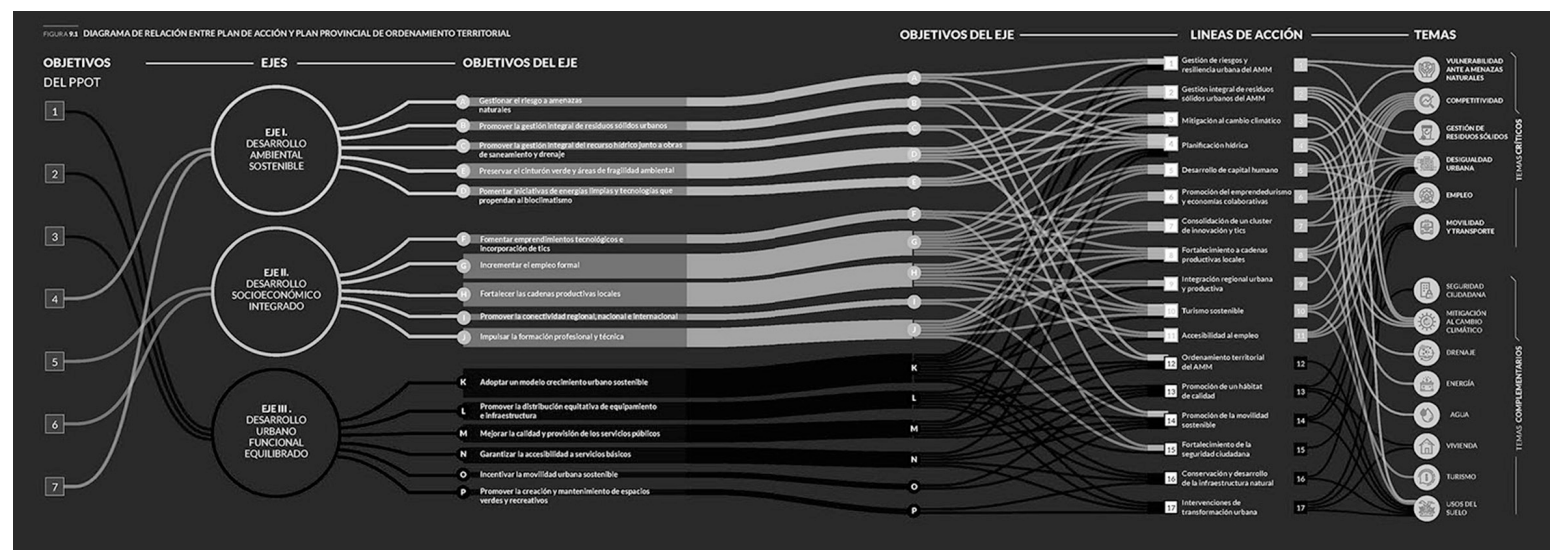

Figura 6 - Diagrama de relación entre el Plan de Acción y el Plan Provincial Territorial. Fuente: Plan de Acción. UNICIPIO, 2018.

\section{Especificidades del planeamiento metropolitano argentino}

A parir de la descripción de las dos principales experiencias de planeamiento metropolitano en Argentina, en este punto se discuten los resultados del análisis individual, retomando los interrogantes planteados en la introducción. Para indagar en los aspectos más específicos y relevantes en relación a las tres dimensiones de partida -la institucional, la instrumental y la procesal-, a continuación se desarrollan tres argumentos derivados del cruce de los casos que, posteriormente, se sintetizan en la Tabla 2.

En primer lugar, podemos decir que los entes metropolitanos tienen un enfoque institucional ambivalente. Por un lado, se conforman desde "desde arriba", dentro del estado provincial y atados al marco integrado de las leyes y objetivos del ordenamiento territorial. En este caso, la relación entre los intendentes adquiere la forma de coalición a favor -o en oposición- al gobierno provincial de turno. En cambio, el segundo tipo de encuadre se da "desde abajo", a partir de la organización voluntaria de los intendentes metropolitanos. Con el tiempo, estás asociaciones cristalizan en instituciones monolíticas, casi autárquicas, ya que nunca se independizan del apoyo del gobierno 
provincial o del de la ciudad capital. En los dos casos analizados, la delicada unidad institucional depende, sobre todo, de dos estrategias. La primera radica en arraigar la conciencia metropolitana de los intendentes a través de discursos persuasivos que sean capaces de reinterpretar los problemas locales en clave regional. La segunda apunta reducir los conflictos políticos, centrando las discusiones exclusivamente en cuestiones técnicas y en proyectos concretos. En definitiva, la institucionalidad de los entes metropolitanos no depende tanto de las leyes o de los acuerdos formales, sino de su capacidad para estabilizar la coyuntura entre los actores.

En segundo lugar, los casos evidencian que el funcionamiento coyuntural de las instituciones plurimunicipales convierte al "nivel" metropolitano un catalizador que debe sintetizar políticas, instrumentos y metodologías tan disímiles como la doctrina del desarrollo sostenible, el enfoque situado del ordenamiento territorial, o la aproximación arquitectónica de los urbanistas. En cualquier caso, se trata de evitar la superposición con los planes locales, enfocando las políticas metropolitanas desde problemáticas específicas como, por ejemplo, el diseño de las vías regionales, la localización de las plantas de tratamiento de residuos o el transporte interurbano. Debido a la complejidad de estos temas, los instrumentos de planeamiento supralocal no suelen ser vinculantes. No obstante, los entes metropolitanos implementan distintos mecanismos para lograr que sus objetivos sean obligatorios. El primero se refiere las instancias de consulta que obligan a los municipios a someter sus expectativas de crecimiento al juicio de los niveles superiores de gobierno, el segundo radica en la implementación de leyes provinciales para proteger los componentes territoriales metropolitanos (los frentes fluviales, el Piedemonte, la red vial primaria, el suelo periurbano, etc.), y el tercero se basa en el apoyo técnico a los municipios para que redacten sus propios planes urbanos, garantizando que incorporen el "ADN metropolitano" en los marcos locales.

Si bien en el proceso de planeamiento metropolitano se contemplan escenarios y costos de inversión, en tercer lugar, podemos argumentar que la gestión supralocal no está atada a un programa de actuaciones, sino a un elenco de obras concretas. No se trata de empezar por el final, sino de demostrar que las políticas metropolitanas son "reales". Así, la incipiente consolidación institucional convierte al programa de acciones -la agenda común plurimunicipal- en un objetivo a mediano plazo. Mientras tanto, el proceso de planeamiento se apoya en diversas fórmulas de participación: talleres, encuestas ciudadanas y mesas de funcionarios y técnicos. El papel protagonista de estos últimos ha sido clave para promover la consciencia de lo metropolitano desde una mirada que enfatiza los aspectos urbanísticos, mientras que la participación de los funcionarios se ha enfocado más en las cuestiones políticas para desentrañar la sutil diferencia entre "cooperación" y "coordinación".

Tabla 2 - Síntesis del análisis cruzado de los casos

\begin{tabular}{|c|c|c|c|}
\hline Dimensión & Variable & AM Rosario & AM Mendoza \\
\hline \multirow{2}{*}{$\begin{array}{l}\text { Contexto } \\
\text { Institucional }\end{array}$} & Marco legal & $\begin{array}{c}\text { Movilización de los intendentes } \\
\text { metropolitanos "desde abajo" a través del } \\
\text { diseño de los planes urbanos locales } \\
\text { (como avance de las directrices de } \\
\text { ordenación territorial). }\end{array}$ & $\begin{array}{l}\text { Conformación del régimen metropolitano } \\
\text { "desde arriba" a través de la Ley de } \\
\text { Ordenamiento Territorial Provincial. }\end{array}$ \\
\hline & $\begin{array}{l}\text { Instituciones } \\
\text { involucradas }\end{array}$ & $\begin{array}{l}\text { Organización voluntaria de las localidades } \\
\text { metropolitanas a partir de la creación de } \\
\text { un ente supramunicipal autárquico. }\end{array}$ & $\begin{array}{c}\text { Alineación de las localidades } \\
\text { metropolitanas a través de un programa } \\
\text { de coordinación supralocal dentro del } \\
\text { Estado provincial. }\end{array}$ \\
\hline \multirow{2}{*}{$\begin{array}{l}\text { Contenido } \\
\text { Instrumental }\end{array}$} & Contenido & $\begin{array}{c}\text { Temas genéricos del planeamiento } \\
\text { urbano local reinterpretados en la escala } \\
\text { regional. }\end{array}$ & $\begin{array}{l}\text { Temas estandarizados del desarrollo } \\
\text { sostenible, articulados con los temas } \\
\text { situados del ordenamiento teritorial. }\end{array}$ \\
\hline & Forma/efecto & $\begin{array}{l}\text { Directrices metropolitanas (indicativas) } \\
\text { complementadas con leyes provinciales } \\
\text { sectoriales y vinculantes. }\end{array}$ & $\begin{array}{l}\text { Plan de acción orientativo } \\
\text { complementado por instancias de } \\
\text { consulta obligatoria. }\end{array}$ \\
\hline \multirow[b]{2}{*}{$\begin{array}{l}\text { Proceso de } \\
\text { Planeamiento }\end{array}$} & Escenarios & $\begin{array}{l}\text { No hay programa ni escenarios. La gestión } \\
\text { comienza por las obras. }\end{array}$ & $\begin{array}{l}\text { Escenarios prospectivos. La gestión se } \\
\text { inicia con la estimación de los costos de } \\
\text { inversión. }\end{array}$ \\
\hline & $\begin{array}{l}\text { Papel de los } \\
\text { técnicos }\end{array}$ & $\begin{array}{l}\text { Intermediadores que combinan instancias } \\
\text { técnicas, dentro del consejo } \\
\text { metropolitano, con instancias } \\
\text { participativas (talleres ciudadanos). }\end{array}$ & $\begin{array}{l}\text { Intermediadores que combinan instancias } \\
\text { técnicas, dentro de las mesas } \\
\text { metropolitanas, con instancias } \\
\text { participativas (encuestas ciudadanas). }\end{array}$ \\
\hline
\end{tabular}

Fuente: Elaboración propia. 


\section{Conclusiones}

En este artículo se apunta a contribuir a la conceptualización del planeamiento metropolitano en América Latina, concibiéndolo como una práctica situada en su contexto. Es en este sentido que, a partir de un estudio de caso comparado de dos experiencias argentinas (Rosario y Mendoza), a través de tres dimensiones analíticas (la institucional, la instrumental y la procesal), intentamos redefinirlo como objeto de estudio, superando el sesgo de las aproximaciones modernistas del período fordista y la idealización de las tradiciones de planeamiento "autorreferenciales" de la casuística del Norte Global. Sin la pretensión de fundar un nuevo tipo o estilo de planeamiento, o de agotar el conocimiento acerca de los casos, los resultados de la comparación pretenden esbozar un enfoque tecnológico del planeamiento metropolitano que, por su singular conjugación de proyectos y estrategias, hemos denominado como "heterodoxo".

Heterodoxo porque, más que anhelar un escenario de integración institucional ideal, saca partido de la posición privilegiada de la escala intermedia para operar en un marco de tensión, entre el verticalismo de la ordenación territorial y la frágil horizontalidad de los gobiernos locales en continuo recambio. Heterodoxo es también el marco instrumental del planeamiento metropolitano que, más allá de la creación burocrática de nuevas herramientas para cada nuevo problema, funciona como un laboratorio tecnológico donde, por un lado, se sintetizan las leyes y los proyectos de todos los niveles de gobierno y, por otro, se combinan productivamente enfoques metodológicos diversos -a veces antagónicos- que van desde el urbanismo morfológico de los arquitectos a los indicadores enlatados de las Naciones Unidas. El planeamiento metropolitano también es heterodoxo en cuanto al tratamiento del tiempo. El contexto de incertidumbre política, económica e institucional torna superfluos a los programas y a los escenarios de actuación. En cambio, la gestión continua, la ejecución de grandes obras y el liderazgo indiscutido han demostrado su capacidad para sostener la coyuntura que moviliza poco a poco la agenda plurimunicipal, haciendo cada vez más tangible el régimen estatal metropolitano.

Deudora del modelo de planeamiento no-euclidiano que proponía John Friedmann a mediados de los noventas, la aproximación heterodoxa metropolitana procura distanciarse del planeamiento tradicional -ortodoxo- propio del modernismo ingenieril, vigente desde los albores de la revolución industrial. El planeamiento ortodoxo, decía Friedmann (1993), es aquel que pretende ser neutral dirigiendo sus objetivos a la "humanidad" sin parcialidades; que pretende ser científico limitándose a las recetas y estándares; que intenta ser operativo limitando su actividad a la producción de documentos, en general, elaborados al margen del escrutinio público; y que anhela ser democrático abogando por una adhesión estricta a los códigos, a la neutralidad afectiva y la tecnocracia apolítica. En cambio, el planeamiento no-euclidiano es aquel que opera en tiempo real, emprendiendo y tomando riesgos; aquel que ata el conocimiento y la acción para superar la resistencia al cambio, adecuando a cada contexto las exigencias de la implementación, más allá de las "recomendaciones" genéricas y las lecciones de manual.

Retomando los resultados de la comparación de los casos argentinos analizados ${ }^{7}$, en este punto, vale la pena comentar algunas cuestiones más sutiles que también contribuyen a la especificidad del enfoque del planeamiento metropolitano heterodoxo.

En cuanto a los aspectos institucionales, los casos analizados ponen en tela de juicio la tesis a favor de un nuevo gobierno supralocal. La "Ciudad Metropolitana", expresión idealizada y voluntarista del nuevo nivel administrativo (Borja, 2016; Pírez, 2005), implicaría, como señala Mirta Levin, “[...] imponer a los intendentes metropolitanos un orden superior, una nueva instancia de subordinación, que desarmaría la

\footnotetext{
${ }^{7}$ Enfatizamos el carácter "reciente" de las experiencias de planeamiento metropolitanas heterodoxas para diferenciarlas de las experiencias anteriores, cuya genealogía queda fuera del alcance de este artículo. En este sentido, si bien hubo otras experiencias notables de planificación metropolitana en América Latina y en Argentina, éstas tuvieron un enfoque generalmente ortodoxo. Los consecutivos planes metropolitanos para el área metropolitana de Buenos Aires -incluida la reciente experiencia del COCAMBA-, son otro claro ejemplo de cómo las sesudas elucubraciones de los tecnócratas y los grandilocuentes anhelos de modernización resultan en documentos destinados a los archivos ministeriales y a las bibliotecas universitarias.
} 
delicada coyuntura que sostiene el ECOM con enorme esfuerzo" ${ }^{\text {. }}$. En cambio, la adhesión de los intendentes a los entes metropolitanos "desde abajo" no solo aumenta su carácter democrático, sino también su poder político, a diferencia de los niveles administrativos más consolidados -y más anquilosados en términos burocráticos-, como el provincial y el nacional. Pero, si los entes metropolitanos se caracterizan por su liviandad (y, a veces, por su precariedad) institucional, ¿en qué radica su poder político? Su poder surge del perfil emprendedor, de la capacidad de gestión y del apoyo en bloque de los intendentes. Este aval es independiente del marco institucional, ya que nunca está garantizado, sino que se construye -y se ratifica- en cada proyecto. El perfil emprendedor también se puede explicar con la metáfora que utiliza Graciela Marty cuando señala que UNICIPIO es una "sombra". Con esto se refiere no solo al rango casi incorpóreo de los entes metropolitanos, sino, sobre todo, a su capacidad para operar entre los espacios capilares de la burocracia e influir en varios niveles administrativos, al mismo tiempo.

En este sentido, la simultaneidad es un aspecto específico del planeamiento metropolitano. Por eso su papel instrumental no se puede tipificar, aunque hay que decir que las metodologías estandarizadas como las del BID permiten que instituciones en ciernes, como UNICIPIO, puedan "entrar en el juego" de la planificación. En particular, el enfoque normalizado del programa Ciudades Emergentes Sostenibles de las Naciones Unidas no permite ajustes a la realidad argentina, ni considera elementos básicos de las áreas metropolitanas como el antagonismo político (diluido bajo el manto de la gobernanza), ni la concurrencia de unidades funcionales con geometría variable, ni la estructuración-histórica, por ejemplo, cuando se mide la pobreza, pero omiten las causas. En el caso del ECOM, en cambio, los técnicos se mantuvieron impasibles a las nociones en boga como "agenda urbana", "ODS", "Horizonte 20-20", "pilares sostenibles", etc. Como señala Levin, "(...) no se trata de privilegiar un enfoque por sobre otro, sino de evitar las recetas genéricas". La orientación del planeamiento metropolitano, más que de un método, depende de la iniciativa (técnica y política), del aprendizaje (instrumental e institucional) y del aprovechamiento de la experiencia situada.

Vale la pena, en este punto, retomar la cuestión sobre la participación en el proceso de planeamiento plurimunicipal. A diferencia de las grandes ciudades capitales, que suelen contar con recursos y antecedentes propios en materia de planeamiento urbano, paradójicamente, la participación metropolitana -a escala regional- es más asequible debido a la relación más directa entre el gobierno y la ciudadanía de las pequeñas localidades de las coronas metropolitanas. En estos casos, los planificadores juegan un papel mediador decisivo, en la medida que interceden entre las localidades, la provincia o la nación. No obstante, para evitar los conflictos políticos e ideológicos, dirigen el desarrollo metropolitano como una cuestión técnica -a veces, dogmáticamente tecnocrática.

Desde un enfoque más pragmático, la adhesión de los intendentes a las políticas supralocales no depende del peso institucional de los entes metropolitanos, ni de la identidad con el nuevo territorio, sino de los beneficios concretos e implícitos en "esas políticas" y en "esa vía" administrativa. El razonamiento estratégico de los intendentes apunta, por un lado, a obtener recursos presupuestarios y, por otro, a incrementar el apoyo político que necesitan para negociar con los niveles superiores de gobierno. Sin embargo, no todas las localidades participan de los entes metropolitanos, y no es casualidad. Tal es el caso de municipios como Puerto General San Martín o Timbúes, sedes de las terminales portuarias más grandes de Argentina, que no dependen de otra administración para obtener recursos -ni están dispuestos a compartir los propios. Del otro lado del mostrador, las instituciones metropolitanas también toman recaudos antes de asociar nuevas localidades al club. En algunos casos, esto implicaría legitimar decisiones de los gobiernos locales cuyos efectos podrían recaer en un compromiso para el ente metropolitano. Por ejemplo, cuando se trata de reconocer la urbanización indiscriminada, sin servicios, o avalar el modelo de urbanización cerrada que promueven algunos intendentes.

En definitiva, el planeamiento metropolitano radica un proceso sofisticado de maduración de un nuevo régimen territorial, construido sobre un marco normativo e instrumental que demanda una aproximación heterodoxa. En este sentido, el trabajo institucional es más importante que la forma de las

\footnotetext{
${ }^{8}$ Mirta Levin, entrevistada por el autor en noviembre de 2018.
} 
instituciones. La evidencia de los casos muestra un notable avance en la gestión del planeamiento, donde la horizontalidad entre los actores locales es la base de la cual pende el delicado equilibrio entre la cooperación y la coordinación metropolitana. Aunque, como vimos, no se trata tanto de un problema tecnológico, sino de aprendizaje, sin el cual no podrían explicarse acciones radicales -como recortar la ciudad capital del mapa- solo para demostrar que la neutralidad partidaria es más que un discurso: no existen proyectos sin estrategias. En este sentido, futuras investigaciones deberán evaluar, por un lado, cuál ha sido el efecto de las políticas metropolitanas desarrolladas en el contexto de cada modelo institucional y, por otro, revisar si las instituciones creadas permanecen operativas más allá del liderazgo de sus caudillos técnicos y sus patronos políticos. Asimismo, queda abierta la cuestión de si las ventajas en la creatividad que permite el planeamiento "heterodoxo" eximen de la posición, más tradicional, de insistir en la conveniencia de modelos más "ortodoxos". Esto último abre nuevos interrogantes sobre la relación entre ambos modelos: ¿son antagónicos o complementarios?, ¿son las etapas del mismo proceso de institucionalización -y modernización- del planeamiento o, por el contrario, responden al reequilibrio del poder territorial y a las luchas entre coaliciones políticas distintas? Siguiendo esta última hipótesis, cabría evaluar hasta qué punto el planeamiento metropolitano heterodoxo -pensado para lugares, objetivos y circunstancias específicas- podría cristalizar en un nuevo nivel administrativo, haciendo que la dependencia técnica y presupuestaria se torne estructural.

\section{Referencias}

Abadia, X. (2002). Àrees metropolitanes comparades: una anàlisi global de metodologies de planejament. Barcelona: Institut d'Estudis Territorials.

Alexander, E. (2002). Metropolitan regional planning in Amsterdam: a case study. The Town Planning Review, 73(1), 17-40. http://dx.doi.org/10.3828/tpr.73.1.2.

Balducci, A., Fedeli, V., \& Curci, F. (2017). Post-metropolitan territories and urban space. London: Routledge.

Blumenfeld, H. (1968). The modern metropolis: its origins, growth, characteristics, and planning. Cambridge: MIT Press.

Borja, J. (2016). Area o Ciutat Metropolitana. Barcelona.

Buenos Aires. (2019). Programa DAMI. Recuperado el 8 de diciembre de 2019, de http://www.dami.uec.gov.ar/elprograma/

Christaller, W. (1966). Central places in southern Germany. Englewood Cliffs: Prentice Hall.

De Carlo, G., \& Quaroni, L. (1962). Relazioni del seminario “La Nuova Dimensione della Città” (p. 198). Stresa: Istituto Lombardo per gli Studi Economici e Sociali.

De Mattos, C. (2001). Metropolización y suburbanización. EURE: Revista Latinoamericana de Estudios Urbano Regionales, 27(80), 5-8. http://dx.doi.org/10.4067/S0250-71612001008000001.

De Miguel González, R., \& Ezquiaga, J. M. (2012). Hacia una ordenación territorial metropolitana renovada en Europa. Los planes de las regiones urbanas de París, Londres, Berlín y Roma. Ciudad y Territorio: Estudios Territoriales, 44(174), 669-688.

Elinbaum, P. (2016). Planes fuera del sistema. Instrumentos ad hoc para la ordenación y gestión de las áreas urbanas plurimunicipales. EURE: Revista Latinoamericana de Estudios Urbano Regionales, 42(127), 29-54. http://dx.doi.org/10.4067/S0250-71612016000300002.

Elinbaum, P. (2018). Planning systems in Latin America: the case of Argentina. disP - The Planning Review, 54, 25-27.

Elinbaum, P., \& Galland, D. (2016). Analysing contemporary metropolitan spatial plans in Europe through their institutional context, instrumental content and planning process. European Planning Studies, 24(1), 181-206. http://dx.doi.org/10.1080/09654313.2015.1036843. 
Elinbaum, P., \& Galland, D. (2017). The evolution of Latin American metropolitan planning: institutions, instruments, processes and cultural traditions. In J. Antunes, J. Simões, \& S. Morgado (Eds.), Abstracts of the AESOP Annual Congress. Lisbon-17: Spaces of dialog for places of dignity: Fostering the European dimension of planning. Lisboa: Universidade de Lisboa.

Esteban, J. (1991). El Fet metropolità. In El Fet metropolità: interpretacions geogràfiques (6th ed., p. 91). Barcelona: Institut d'Estudis Metropolitans de Barcelona.

Esteban, J. (1998). Elementos de ordenación urbana. Barcelona: Edicions UPC.

Esteban, J. (2012). El Pla Territorial Metropolità de Barcelona en el planejament territorial de Catalunya. Papers: Regió Metropolitana de Barcelona: Territori, Estratègies, Planejament, (55), 20-31.

European Union. (1997). The EU compendium of spatial planning systems and policies. Luxembourg: Office for Official Publications of the European Communities.

Faludi, A. (1996). Rationiality, critical rationalism, and planning doctrine. In S. J. Mandelbaum, L. Mazza \& R. W. Burchell (Eds.), Explorations in Planning Theory (pp. 65-82). New Brunswick: Center for Urban Policy Research, Rutgers University.

Faludi, A. (2000). The performance of spatial planning. Planning Practice and Research, 15(4), 299-318. http://dx.doi.org/10.1080/713691907.

Faludi, A., \& Van der Valk, A. (1994). Rule and order: dutch planning doctrine in the twentieth century. Dordrecht: Kluwer Academic Publishers. http://dx.doi.org/10.1007/978-94-017-2927-7.

Farinós, J. (2006). Governance of territorial and urban policies from EU to local level: final report of ESPON project 2.3.2. Luxemburg: The ESPON Monitoring Commitee.

Font, A. (2000). La experiencia reciente en Cataluña. Planeamiento urbanístico para el siglo XXI. Urban, (5), 60-82. Fouchier, V. (2010). Le Bassin parisien, une méga-région? Les Cahiers, (153), 4-6.

Friedmann, J. (1993). Toward a non-euclidian mode of planning. Journal of the American Planning Association, 59(4), 482-485. http://dx.doi.org/10.1080/01944369308975902.

Galland, D., \& Elinbaum, P. (2018). A "field" under construction: the state of planning in Latin America and the southern turn in planning. disP - The Planning Review, 54(1), 18-24.

Geddes, P. (1915). Cities in evolution. London: Williams \& Norgate.

Gottmann, J. (1961). Megalopolis: the urbanized Northestern Seaboard of the United States. New York: Twenttieth Century Fund.

Healey, P. (2006). Collaborative planning: shaping places in fragmented societies (2nd ed.). Basingstoke: Palgrave Macmillan. http://dx.doi.org/10.1007/978-1-137-08600-6.

Indovina, F. (2007). La metropolización del territorio. In A. Font (Ed.), L'explosió de la ciutat: morfologies, mirades $i$ mocions sobre les transformacions territorials recents en les regions urbanes de l'Europa Meridional (pp. 20-43).

Barcelona: COAC.

Janin Rivolin, U. (2008). Conforming and performing planning systems in Europe: an unbearable cohabitation. Planning Practice and Research, 23(2), 167-186. http://dx.doi.org/10.1080/02697450802327081.

Julià, J. (2006). Redes metropolitanas. Barcelona: GG Gustavo Gili.

Lefèvre, C. (2009). Gouverner les métropoles. Paris: Dexia; LGDJ-Lextenso.

Marcelloni, M. (2002). Roma e la pianificazione strategica. Roma: Urbanistica Informazioni.

Meijers, E., Romein, A., \& Hoppenbrouwer, E. (2003). Planning polycentric urban regions in North West Europe: value, feasibility and design. Delft: DUP Science.

METREX. (2007). Framework: policentricity in a better European territorial balance. Glasgow: METREX. 
Nadin, V., \& Stead, D. (2008). European spatial planning systems, social models and learning. disP: the planning. RE:view, 44(1), 35-47.

Nel·lo, O. (2017). El proceso de urbanización: motor y expresión de las transformaciones sociales y territoriales. In J. Romero (Ed.), Geografía humana de España: curso de introducción (pp. 290-366). Barcelona: Tirant lo Blanch.

Neuman, M., \& Hull, A. (2009). The futures of the city region. Regional Studies, 43(6), 777-787. http://dx.doi.org/10.1080/00343400903037511.

Newman, P., \& Thornley, A. (1996). Urban planning in Europe: international competition, national systems, and planning projects. London: Routledge.

Orellana Ossandón, A. M., Bannen Lanata, P., Fuentes Arce, L. A., Gilabert Peralta, H., \& Pape Casale, K. (2013). Huellas del proceso de metropolización en Chile. Revista INVI, 28(77), 17-66. http://dx.doi.org/10.4067/S071883582013000100002 .

Pírez, P. (2005). Buenos Aires: ciudad metropolitana y gobernabilidad. Estudios Demográficos y Urbanos, 20(3), 423-447. http://dx.doi.org/10.24201/edu.v20i3.1206.

Ren, X., \& Keil, R., eds (2017). The globalizing cities reader. London: Routledge. http://dx.doi.org/10.4324/9781315684871.

Rojas, E., Cuadrado-Roura, J., \& Fernández Güell, J. (2005). Gobernar las metrópolis. Washington: Banco Interamericano de Desarrollo.

Roodbol-Mekkes, P., van der Valk, A. J. J., \& Altes, W. K. K. (2012). The Netherlands spatial planning doctrine in disarray in the 21st century. Environment \& Planning A, 44(2), 377-395. http://dx.doi.org/10.1068/a44162.

Selva, R. (2017). Planeamiento metropolitano en América Latina: experiencias recientes. RIURB, (13), 1-2.

Simmons, M. (2000). Planeamiento urbano territorial en el siglo XXI. Urban, (5), 40-49.

Soja, E. (2000). Postmetropolis: critical studies of cities and regions. Malden, MA: Blackwell Pub.

van Duinen, L. (2004) Spatial Imagery. The Emergence and Development of New Planning Concepts in Dutch National Planning Policy (PhD dissertation). University of Amsterdam, Amsterdam.

van Duinen, L. (2013). Mainport and corridor: exploring the mobilizing capacities of Dutch spatial concepts. Planning Theory \& Practice, 14(2), 211-232. http://dx.doi.org/10.1080/14649357.2013.782423.

Vicente, J. (2003). ¿Nuevas palabras, nuevas ciudades? Revija za Geografijo, (2), 79-103.

\section{Editor: Rodrigo Firmino}

Recibido: Dic. 18, 2019

Aprobado: Mayo 25, 2020 